\title{
In the Midst of Life-Cell Death: What Is It, What Is It Good for, and How to Study It
}

\author{
John Silke $e^{1,2,5}$ and Ricky W. Johnstone $\mathrm{e}^{3,4,5}$ \\ ${ }^{1}$ The Walter and Eliza Hall Institute of Medical Research, Melbourne, Victoria 3052, Australia; ${ }^{2}$ Department \\ of Medical Biology, University of Melbourne, Melbourne, Parkville, Victoria 3050, Australia; ${ }^{3}$ Peter MacCallum \\ Cancer Centre, Melbourne, Victoria 3002, Australia; ${ }^{4}$ The Sir Peter MacCallum Department of Oncology, \\ University of Melbourne, Melbourne, Victoria 3052, Australia
}

\begin{abstract}
Cell death, one of the most fundamental biological processes, has not made it into the public consciousness in the same way that genetic inheritance, cell division, or DNA replication has. Everyone knows they get their genes from their parents, but few would be aware that even before they were born a lot of essential cell death has shaped their development. The greater population, for the most part, is blissfully unaware that every day millions of their own cells die in a programmed way and that this is essential for normal human physiology — their well-being, in fact. Nowhere is the burial liturgy, "In the midst of life we are in death," more apt. Despite this public underappreciation, cell death research is a major industry. A search in PubMed for "apoptosis," a special form of cell death that is caused by caspases, returns approximately 280,000 hits. The intense research interest arises from the realization that abnormal cell death responses play an important role in two of the biggest killers in the western world: cancer and cardio/cerebrovascular disease. Furthermore, the manner in which cells die can also influence the development of autoimmune and autoinflammatory diseases. It is therefore of paramount importance to ensure that experiments accurately quantitate and correctly identify cell death in all its guises. That is the goal of this protocol collection.
\end{abstract}

In this introduction we take a very broad overview of the research area. Rather than try and attempt anything too profound, we provide a brief taster of some of the main ideas and questions in the field. As it is such a vibrant area of research, it would be impossible to summarize every facet of the area, and we would not even try. Rather, because this is a collection of protocols designed to allow the reader to experimentally explore questions about cell death, we will describe some basic concepts and pose some of the outstanding questions in the area.

One basic concept is that there are many different forms of cell death that have been identified and we therefore begin with very brief explanations of different types of cell death.

\section{Accidental Cell Death Induced by Physical or Chemical Trauma}

All cells are mortal - they can be killed by trauma, toxins, excessive temperatures, and chemical concentrations and other noxious stimuli. This type of cell death does not feature strongly in this

\footnotetext{
${ }^{5}$ Correspondence: j.silke@latrobe.edu.au; ricky.johnstone@petermac.org

(C) 2016 Cold Spring Harbor Laboratory Press

Cite this introduction as Cold Spring Harb Protoc; doi:10.1101/pdb.top070508
} 
collection. Noxious stimuli can activate programmed cell death pathways that this protocol collection does deal with, but at sufficiently high concentrations or intensities, these pathways may well be irrelevant as far as the ultimate fate of the cell is concerned.

Apoptosis

Apoptosis does not describe a cell death pathway but rather a cell death phenotype. The phenotype that the word describes consists of cell shrinkage, plasma membrane blebbing, nuclear chromatin condensation, and genomic DNA fragmentation among other things. Because these processes depend on caspase activity, apoptosis is, by definition, a caspase-dependent process. Initiator caspases are usually considered to become activated by conformational changes induced by oligomerization enforced by an upstream adaptor molecule, such as APAF-1 (caspase-9) or FADD and RIPK1 (caspase-8) in mammals (Boatright et al. 2003). These so-called initiator caspases, caspase- 8 and caspase-9, become activated and are then able to process downstream (or executioner) caspases (e.g., caspase-3 and caspase-7) to induce their activation. Because the apoptotic morphology is widely conserved throughout evolution, conserved caspase substrates exist (Crawford et al. 2012) as nicely detailed by Gavin McStay and Doug Green (see Introduction: Measuring Apoptosis: Caspase Inhibitors and Activity Assays [McStay and Green 2014]). Frequently these are "effector" caspase substrates and their cleavage leads to the typical apoptotic morphology. For example, cleavage of ICAD, the inhibitor of the DNase CAD, by caspase-3 liberates $\mathrm{CAD}$ and results in DNA fragmentation. Likewise cleavage and inactivation of the enzymes involved in asymmetric distribution of phosphatidylserine (PS) in the plasma membrane, as well as cleavage and activation of flipase enzymes results in exposure of PS on the extracellular leaflet of the plasma membrane. Methods to detect and accurately measure molecular, biochemical, and biological hallmarks of apoptosis in mammals, flies, and worms are extensively covered in this collection. Moreover, advanced imaging techniques to assess dynamic apoptotic processes are now available, as showed in elegant detail by Lisa Bouchier-Hayes and Markus Rehm (see Introduction: Imaging-Based Methods for Assessing Caspase Activity in Single Cells [Parsons et al. 2015]).

\section{Intrinsic Apoptosis?}

The term "intrinsic apoptosis" is very frequently used and just as frequently misused. The signal that leads to activation of APAF-1/caspase-9/caspase-3 and an apoptotic morphology in mammals is the release of cytochrome $c$ from the intermembrane space of mitochondria. Typically cytochrome $c$ is released in response to such inducers of cell death as DNA damaging drugs, toxins, and lack of growth factors. Much developmental cell death is likely to be of this type. The APAF-1/caspase-9/caspase-3 has been termed the intrinsic apoptosis pathway because the signals are generated from within cells. However, and it is an important point to understand, the "point of no return" for a cell to survive has usually preceded this activation.

Cytochrome $c$ is released following activation of Bax/Bak, a process covered in a series of protocols by Grant Dewson (see, e.g., Protocol: Investigating Bak/Bax Activating Conformation Change by Immunoprecipitation [Dewson 2015]). These proteins, once activated via the activities of $\mathrm{BH} 3$ proteins, are able to damage mitochondrial membranes and cause release of cytochrome $c$. In this case, if caspase inhibitors were applied to cells, they might be able to stop apoptosis (the particular morphology often associated with Bax/Bak-mediated cell death). But they would be unable to prevent cell death because, even if caspases are inhibited, the loss of cytochrome $c$ and mitochondrial membrane disruption will cause cells to die from lack of ATP. Thus Bax/Bak-mediated cell death is often associated with caspase activation and cell death but it is not synonymous with "intrinsic apoptosis."

\section{Extrinsic Apoptosis?}

The signals that lead to the activation of caspase- 8 in mammals are usually considered to be transmitted by plasma membrane receptors, often classified as "Death Receptors" such as Fas, TNF, and TRAIL-R, that respond to ligands delivered by other cells. Thus, cell death consequent on activation of 
caspase- 8 is often considered to be via an "extrinsic" pathway. More recently, it has become clear that activation of caspase- 8 to induce cell death can be accomplished by intracellular platforms including the "Ripoptosome" (containing RIPK1) but also MAVS/RIG and TLRs (Feoktistova et al. 2011; Tenev et al. 2011). In "extrinsic" apoptosis pathways, it is possible that blocking caspase- 8 is sufficient to prevent cell death; however, as we shall discuss below, blocking caspase- 8 may nevertheless trigger an alternative form of cell death called "necroptosis." Marion MacFarlane and Pascal Meier provide insight into these molecularly linked, yet phenotypically diverse processes and tools to study them (see Introduction: Biochemical Analysis of Initiator Caspase-Activating Complexes-The Apoptosome and DISC [Langlais et al. 2015] and Introduction: Techniques to Distinguish Apoptosis from Necroptosis [Feoktistova et al. 2015]).

Finally, in some cells, activation of caspase- 8 by plasma membrane receptors is insufficient to cause adequate caspase- 3 activation to mediate the demise of a cell, yet is able to cause cell death. In these cells, caspase- 8 is able to process and activate the $\mathrm{BH} 3$ protein Bid, and this activated $\mathrm{BH} 3$-only protein leads to the activation of Bax/Bak and cell death. Thus, as with intrinsic apoptosis, the term "extrinsic apoptosis" is potentially ambiguous and should be used and interpreted with caution.

\section{Perforin and Granzyme B-Induced Cell Death}

Certain cells, such as cytotoxic T cells and natural killer cells, are able to induce cell death by secreting a pore-forming protein, perforin, and delivering a class of serine proteases, called granzymes, into cells. Granzymes can enter cells in the absence of perforin, but perforin increases the efficiency and potency of delivery. Granzyme B has a unique substrate specificity and recognizes and cleaves the same short peptide motif that caspases cleave. Thus Granzyme B is able to cleave and activate downstream or effector caspases such as caspase-3, as well as the BH3 protein Bid (Waterhouse and Trapani 2002).

\section{Caspase Activation Is Not Synonymous with Cell Death}

Although caspase cleavage is frequently used to assess activation of caspases, it is not a required event for their activation. This is obviously true where initiator caspases are involved because conformational change induced by oligomerization platforms is all that is required to activate them (Boatright et al. 2003). It appears that caspase processing is probably a mechanism to ensure complete and irreversible activation. However, in most normal developmental situations, it is not easy to detect activated caspases, even in situations like the developing brain where there are supposed to be millions of cell deaths occurring because even early-stage apoptotic cells are rapidly engulfed. This phenomenon is discussed by Michael Bots and colleagues (see Introduction: Measuring Apoptosis in Mammals In Vivo [Newbold et al. 2014]).

Second, although apoptotic stimuli induce the activation of caspases, it has again become clear that even so-called apoptotic caspases may perform roles in addition to dismantling cells (Shalini et al. 2015). One of the best examples of alternative activity is that of caspase-8, which is linked to, among other things, the processing of cytokines and the inhibition of inflammasome activation. However, apoptotic caspases have also been linked to regulating cell cycle and other important physiological functions such as immune responses and cell fate determination (Shalini et al. 2015). This should not be too surprising because caspases, such as caspase-1, whose primary role appears to be proteolytic activation of cytokines such as IL-1 $\beta$ and IL-18, can nevertheless also induce cell death.

Thus, outstanding questions in this area are as follows.

1. How can apoptotic caspases be regulated such that they do not induce apoptosis?

2. To what extent does the extensive processing of caspases during apoptosis represent a physiological and/or pathological scenario? After all, even limited caspase activation may be sufficient to induce PS exposure and engulfment of a cell in vivo. It is possible to observe activated caspases in vivo in certain disease or mutant scenarios (i.e., in situations where massive cell death occurs or dead cells are ineffectively cleared). But in tissues where substantial developmental cell death occurs, such as in the thymus and brain, it is actually very difficult to quantify the degree of apoptosis because the 


\section{Pyroptosis}

dying cells are so rapidly cleared from the microenvironment following PS exposure. Aspects of this are covered by Michael Bots and colleagues (see Introduction: Measuring Apoptosis in Mammals In Vivo [Newbold et al. 2014]).

Pyroptosis has certain similarities with necroptosis and necrosis. Like necrosis and necroptosis, pyroptosis is believed to result in cell swelling and the release of cellular contents, but it also has other apoptotic features such as DNA fragmentation and chromatin condensation. And, like apoptosis, it is caused by caspases. Both caspase- 1 and caspase-11, in mice, have been implicated in this type of cell death, and depending on the stimulus, either may be used. It has been claimed that pyroptosis leads to release of IL- $1 \beta$, IL- $1 \alpha$, and IL-18; however, more recent kinetic studies show that these cytokines, two of which are processed by caspase-1, are released before "cell death" (Gross et al. 2012). Although there are no caspase-1- or caspase-11-specific protocols, the assays to monitor caspase activity described in this collection are broadly applicable to all caspases (see Introduction: Imaging-Based Methods for Assessing Caspase Activity in Single Cells [Parsons et al. 2015]) and Introduction: Measuring Apoptosis: Caspase Inhibitors and Activity Assays [McStay and Green 2014]).

Mice deficient in these so called "inflammatory" caspases are highly susceptible to infection by bacteria, particularly intracellular pathogens; however, it is difficult to segregate the effects due to loss of cell death from those due to the loss of secretion of inflammatory mediators. Where it has been attempted, by testing mice deficient in signaling by the main cytokines that are dependent on caspase activity, IL-1 $\beta$, IL-18, and IL- $1 \alpha$, but which retain the ability to activate caspase- 1 and cause pyroptosis, the loss of cytokine production is far more detrimental than loss of caspase- 1 activity (Aachoui et al. 2013). Most recently, a link between inflammasomes and caspase-8/caspase-3 activation has been described; thus, activation of inflammasomes, such as those mediated by AIM2 and NLRP3, can induce apoptosis. One study showed that lower doses of the inflammasome-activating stimulus preferentially induced apoptosis (Sagulenko et al. 2013).

Normally it is considered that a primary purpose, for the host, of infected cells undergoing cell death is to prevent the pathogen replicating and to expose it to the immune system. But pyroptosis is most frequently induced in the laboratory by bacterial PAMPs, not by infection. Do high doses of PAMPs mimic intracellular infection? Once dead, a cell cannot secrete more than its stockpile of cytokine; therefore, pyroptosis might be considered an antiinflammatory response or a mechanism to limit chronic inflammation that may ultimately be detrimental to the host (Martin et al. 2012). But this seems at odds with the idea that the release of intracellular contents may be inflammatory. The regulation of this process and how it is finely tuned and controlled to ensure maximal value to the host organism remains an area of intense study. In broader terms, the physiological importance of pyroptosis has yet to be fully articulated. If cells do not require pyroptosis to release inflammatory cytokines, why do they undergo this type of death? Given the potential involvement of caspase- 8 in inflammasome activation, do inflammasome-activated cells only undergo a pyroptotic death?

\section{Necrosis and Necroptosis}

Necrosis is a type of cell death that is morphologically almost opposite to that of apoptosis. Instead of cell shrinkage, there is cell and organelle swelling, and there is a loss of intracellular contents, rather than a careful dismantling. In contrast to apoptosis, it was considered an accidental type of cell death. Methods to delineate necrosis from apoptosis are discussed by Nigel Waterhouse and colleagues (see Introduction: Dead Cert: Measuring Cell Death [Crowley et al. 2015a]). However, it has recently become apparent that in some cases this cell death morphology can also occur in a programmed manner. To indicate this necrotic cell morphology and the genetically encoded nature, this cell death has been coined "necroptosis." This cell death is caused by MLKL, and this protein, in an as-yet unknown manner, permeabilizes plasma membranes. MLKL can be activated by phosphorylation by RIPK3, and RIPK3 can in turn be activated by RIPK1, although RIPK1 is not always required. Activation of MLKL is often experimentally achieved by stimulating the receptors that initiate the extrinsic apoptosis 
pathway and by preventing caspase- 8 activation. Thus, one of the common ways to induce necroptosis is to add a ligand such as TNF and inhibit caspase- 8 with a caspase inhibitor. In this pathway, caspase- 8 cleaves RIPK1 and possibly RIPK3 to prevent them from activating MLKL. Pascal Meier, Martin Leverkus, and colleagues provide detailed methods to identify and quantify necroptotic features (see Introduction: Techniques to Distinguish Apoptosis from Necroptosis [Feoktistova et al. 2015]).

Cells displaying a necroptotic morphology are not particularly easy to observe in vivo, in contrast to apoptotic cells, where it is possible to detect cleaved DNA (using a TUNEL assay) or activated caspases in tissues. Necroptosis has been implicated as an active mediator of inflammation, and there is circumstantial evidence for a role in Crohn's disease, ulcerative colitis, or allergic colitis (Pasparakis and Vandenabeele 2015). Further-proposed pathological roles for necroptosis include situations of acute tissue damage, such as stroke and myocardial infarction, and in ischemia-reperfusion injury. Exactly how necroptosis contributes to the initiation, amplification, and/or maintenance of an inflammatory state and how cell autonomous or extrinsic factors regulate this process remain to be determined. However, the evidence for an important pathophysiological role for necroptosis is mounting, and the methods described by Pascal Meier, Martin Leverkus, and colleagues will facilitate further experimental investigation in this area (see Introduction: Techniques to Distinguish Apoptosis from Necroptosis [Feoktistova et al. 2015]).

\section{Autophagy-Dependent Cell Death}

Autophagy-dependent cell death is, like apoptosis, morphologically defined. The term really describes cell death with autophagy. Autophagy is an essential cellular process that disposes of organelles, cytosolic bacteria, and cytosol via a membrane vesicle mechanism that delivers these components to lysosomes to be degraded and recycled. Of all the types of cell death that are discussed in this collection, autophagy-dependent cell death is perhaps the most controversial and most representative of the fact that cell death maybe a consequence of an adaptive cellular response. There are clear cases, such as the remodeling Drosophila larval gut during metamorphosis, where the loss of genes required for autophagy reduces cell death, indicating that this is truly cell death caused by autophagy. Involuting Drosophila salivary glands also use autophagy; however, unlike the gut, caspases are also required for complete involution. Autophagy-dependent cell death also plays a role in developmental cell death in plants, such as Arabidopsis, and stalk formation in the single-celled organism Dictyostelium (Nelson and Baehrecke 2014).

However, from yeast to mammals, it is clear that autophagy is primarily used as a cell homeostasis and survival mechanism. The essential requirement for autophagy to dispose of organelles and recycle cellular components has been shown by genetic experiments. For example, when tissue-specific knockout mice of essential autophagy genes are analyzed, they accumulate damaged mitochondria that in turn cause severe disruption to cellular function. The ability of this process to recycle components also makes it valuable/vital in times of nutrient starvation and stress. A series of protocols within this collection describe contemporary methods used in mammalian, Drosophila, and Caenorhabditis elegans systems to study and read out molecular and biochemical features of autophagy (see, e.g., Protocol: LysoTracker Staining to Aid in Monitoring Autophagy in Drosophila [DeVorkin and Groski 2015] and Introduction: Detection of Autophagy in Caenorhabditis elegans [Palmisano and Meléndez 2015]). The discussion by Katja Simon and colleagues (Introduction: Techniques for the Detection of Autophagy in Primary Mammalian Cells [Puleston et al. 2015]) summarizes the types of autophagy, the cellular role it plays, and the chief molecular components required for it. Furthermore, they make it clear that the most important consideration/question in this field is whether autophagy executes cell death in vivo.

NETosis

Neutrophils, and some other myeloid cell types, have the ability to expel net-like structures containing their nuclear DNA coated with histones and proteases from their granules, such as elastase. The structures have been named neutrophil extracellular traps (NETs) and their formation is usually 
linked to plasma membrane disruption and cell death, hence NETosis. The fundamental questions in this area are: What is the physiological function of NETs? Are they a neutrophil host defense mechanism to disable bacteria and fungi or at least hinder their dissemination? Or are they a consequence of cell death induced by pathogen toxins? Is there a molecular link between NETosis and other forms of cell death such as necroptosis? And, finally and remarkably, there is even some question as to whether expulsion of nuclear DNA necessarily leads to cell death (Yipp and Kubes 2013).

\section{THE BIGGER PICTURE}

In this section, we have highlighted points that often get overlooked when investigating cell death and therefore are pertinent to raise by way of introduction to the content of this collection.

A core question not restricted to cell death and very topical is to what extent we can rely on published research (Begley and Ellis 2012; Errington et al. 2014; Morrison 2014; Begley and Ioannidis 2015). The scientific approach has always been one of healthy skepticism, and a key tenet is that others should be able to reproduce a scientific discovery for it to be valid. Francis Bacon, considered by many to be the father of modern science, recognized that following academic dogma and not asking one's own questions about the world obstructed scientific reasoning and discovery (Bacon 1620). However, increasing complexity and specialization, among other things, often makes replication hard in practice. Therefore, Vaux (2015) provides some useful advice for interpreting published research and for communicating one's own research to enable reproducibility with reference to cell death research.

Another point that is often overlooked in the field is the "simple" question of when can we consider a cell to be "dead"? As Vaux (2015) states, "at first glance it seems trivial to decide whether a cell is alive or dead." And the absurdity of the idea that anything can be both alive and dead is captured in such diverse areas as particle physics, Schrodinger's cat, and popular culture-for example, the song Grandad from Jake Thackeray reads "Although they stuffed him in a coffin and read out the will, Although he's six foot deep in darkness he'll never lie still.”

It has been proposed that a cell should be considered dead if the integrity of the plasma membrane is irretrievably lost; the cell, including its nucleus, has undergone fragmentation; or its "corpse" has been engulfed by an adjacent cell (Kroemer et al. 2009). These are perfectly fine criteria but, as discussed above and by Michael Bots and colleagues (see Introduction: Measuring Apoptosis in Mammals In Vivo [Newbold et al. 2014]), in vivo the fact that an apoptotic cell "looks a little pale" (i.e., exposes PS), and long before membrane permeabilization occurs, can be sufficient to promote its rapid engulfment and disposal in vivo. On the other hand, the fact that engulfed cells can sometimes escape suggests that really only the first two are true markers of cell death (Galluzzi et al. 2015). Whatever weight one wishes to give these findings, it is very clear that apoptotic cells, which are so easy to distinguish in vitro, are very difficult to detect in vivo unless there is massive co-ordinated cell death that overwhelms the disposal of dead cells. Indeed, even in C. elegans, where dead cells can persist for $\sim 40 \mathrm{~min}$ and can be easily distinguished with the appropriate microscope setup (see, e.g., Protocol: Visualizing Apoptosis in Embryos and the Germline of Caenorhabditis elegans [Lant and Derry 2014]), it was the use of ced-1 mutants that are defective in dead cell disposal that allowed the identification of other cell death mutants. Thus one has to ask in what circumstances the intricate downstream dismantling of cells by caspases that takes several hours post PS exposure in vitro is relevant in vivo. One very interesting addition to this discussion is the finding that Apaf-1/caspase-9/caspase-3-induced apoptosis prevents production of IFNs in vivo. Specifically, Apaf-1/caspase-9/caspase-3 activation was shown to be necessary to correctly dispose of mitochondrial DNA. In the absence of these effectors, mitochondria become leaky and mitochondrial DNA is able to activate cytosolic DNA sensors to stimulate IFN production (Rongvaux et al. 2014; White et al. 2014). Along with a host of other evidence (Yoshida et al. 2005; Hanayama et al. 2006; Suzuki et al. 2013; Segawa et al. 2014), this indicates that a primary function of apoptosis is to promote the clearance of dead cells and thereby prevent an inflammatory or immune reaction. Whatever the purpose, in multicellular organisms, a cell can be effectively dead long before it displays many of the classical biochemical signatures of cell death. 
The flip side of this question is whether a cell is alive. This question turns out to be difficult to answer when we consider the context in which it is usually asked. This question is often posed in short-term cell death assays that cannot evaluate whether a particular intervention or insult has simply delayed death, which is unlikely to be of much interest, or prevented it. Long-term survival assays in vitro are not necessarily easy to perform and usually conflate the two parameters of function and survival. For example, in vitro colony assays are useful to determine if cells that have the capacity to divide and form clones have retained that capacity following a death stimulus (see Protocol: Measuring Survival of Adherent Cells with the Colony-Forming Assay [Crowley et al. 2015b] and Protocol: Measuring Survival of Hematopoietic Cancer Cells with the Colony-Forming Assay in Soft Agar [Crowley and Waterhouse 2015]). If they have, then they were undoubtedly alive when seeded onto the tissue culture plate, quod erat demonstratum. However, this type of assay is not applicable to many cells, such as postmitotic neurons, whose death we might be interested in and wish to prevent. And even the colony assay is open to the criticism that the cells might still be living and functioning as ascertained by every other measure but have lost the ability to divide.

Furthermore biologists interested in multicellular animals are rarely concerned whether cells have a vegetative existence and much more interested in whether they have a functional existence. Thus we often determine whether cells display the biochemical signature of cell death, which as this collection shows is relatively straightforward to determine, when what we really want to know is whether the cells are alive and functioning, which is often far more difficult to ascertain in vitro. From a pragmatic viewpoint, as biologists, what we are interested in, more often than not, is whether a cell is alive and functioning. If we consider a neuron in an ischemic brain that has been prevented from dying by a novel cell death inhibiting drug, what we as drug deliverers want to achieve is to prevent and not delay its death and to maintain its functional existence not a vegetative state. Thus, although this is conflating two different issues (i.e., death and function) from a pragmatic perspective, if we wish to clinically prevent ischemic reperfusion brain injury, it is probably not enough to prevent cell death. However, in other scenarios, such as pyroptotic or necroptotic deaths that release DAMPs that activate the immune system and might thereby contribute to auto-inflammatory diseases, it maybe simply sufficient to stop cell death.

Naturally in vivo experiments often allow us to address this live/dead function conundrum directly, but it is very worthwhile considering that these experiments are far more dependent on genetic background than is widely acknowledged. In mammals, the loss of the key effector molecules of the intrinsic apoptosis pathway, apaf-1, caspase-9, and caspase-3, results in exencephaly in murine embryos and consequent lethality. In C57BL/6 mice, the loss of Bax and Bak, which are required for mitochondrial permeabilization, likewise result in failure of embryonic development. However it is worth remarking that many of these developmental failures are not absolute: Occasional Bax/Bak double knockout mice are born (Lindsten et al. 2000), and the effect of the loss of caspase- 9 and apaf-1 is very dependent on the background strain of the knockout mice. In yet another example, $\operatorname{casp} 3^{-1-}$ mice generated on a mixed 129/Sv C57BL/6 background showed exencephaly and consequent perinatal lethality. However, when backcrossed further onto the C57BL/6 background, these knockout mice survive through adulthood with no obvious defects, whereas pure $129 / \mathrm{Sv} \operatorname{cas} p 3^{-/-}$mice are embryonic lethal (Zheng 2000).

Another point often overlooked is whether cell death pathways really occur in isolation from each other. A prime example of this is the field of lysosomal membrane permeabilization (see Introduction: Methods for Probing Lysosomal Membrane Permeabilization [Jäättelä and Nylandsted 2015] and Introduction: In the Footsteps of Lysosomal Membrane Permeabilization [Repnik et al. 2015]). Thus, the permeabilization of lysosomal and late endosomal membranes can result in the release of their lytic cargo into the cytosol and the activation of caspases, as well as the release of lysosomal proteases that can act as executioner proteases in their own right. On the other hand, apoptosis can be associated with the destabilization of these membranes and release of the contents of these organelles. This intimate link between these two pathways highlights the difficulties in studying these events as well as another fallacy that Francis Bacon identified-the very human tendency to categorize and impose more order than it finds. However these links exist in other pathways. It seems clear that reduced 
caspase- 8 activity can lead to necroptosis, because caspase- 8 limits activation of RIPK1 and RIPK3. But there still might be sufficient caspase- 8 activity to activate caspase- 3 so that we have a type of chimeric cell death. The tendency is for experimenters to look at what they want to see, and thus studies that exclude chimeric cell death are not abundant.

\section{WHAT REMAINS TO DO AND FIND OUT?}

With more than 280,000 articles in the mainstream scientific literature on "apoptosis" alone, we have clearly learned a lot about programmed cell death in recent years. Nevertheless the fact that this is a collection of experimental techniques makes it plain that there is still much to learn that will not be merely incremental advances in knowledge. Technological advances often precede and drive discovery, but there are a number of such advances that simply require the appropriate molecular tools to be fully used.

\section{Markers and Reporters for Cell Death}

For more recently described types of cell death, such as necroptosis and pyroptosis, there is still a lack of good markers that can be used in vitro. The recent development of a human-specific phosphoMLKL antibody (Wang et al. 2014) has helped for necroptosis, but more such tools are needed.

There is also a dearth of good markers and reporters for autophagy, pyroptosis, and necroptosis occurring in vivo in mammals, even in fixed tissues. This is unsurprising when we consider that in the well-researched area of apoptosis, most mammalian and Drosophila in vivo assays require fixing of tissues and cannot be used in real time (see Introduction: Measuring Apoptosis in Mammals In Vivo [Newbold et al. 2014] and Introduction: Studying Apoptosis in Drosophila [Denton and Kumar 2015]). This is one of the attractions of transparent organisms such as C. elegans and zebrafish, where apoptotic and autophagic cells are far easier to detect in situ with conventional microscopy techniques (e.g., see Protocol: Visualizing Apoptosis in Embryos and the Germline of C. elegans [Lant and Derry 2014] and Introduction: Detection of Autophagy in Caennorhabditis elegans [Palmisano and Meléndez 2015]). The next technological frontier will be to develop reporters that are able to detect cell death in real time in vivo. With such reporters, questions about the physiological relevance of particular types of cell death will be quickly resolved. Advances in microscopic techniques and equipment will undoubtedly contribute to such a revolution but molecular tools are still sorely needed.

Genetic Manipulation

The impact of new technologies is illustrated beautifully by the emerging role played in research by the relatively new technologies of CRISPR and TALENs. Genetic experiments are still some of the most reliable evidence for the involvement of a particular gene/protein in a particular pathway and the ability to now not only rapidly delete but even tag endogenous molecules with these technologies is likely to immediately lead to an increase in the reporter constructs that will help transform research of endogenous and physiological cell death (Wang et al. 2013; Yang et al. 2013). The CRISPR approach is also highly suited to high-throughput death assays; the contribution by Kaylene Simpson and colleagues (see Introduction: High-Throughput Approaches to Measuring Cell Death [Saunders et al. 2014]) gives examples of such assays and provides important design considerations.

\section{Therapeutics and Small Drug-Like Molecules}

As outlined elsewhere in this collection, defects in cell death pathways result in diseases. Indeed in the cancer setting it has been appreciated for some time that chemotherapeutic drugs, used for decades in the clinic, work by inducing apoptosis and that drug resistance can be mediated by defects in the apoptotic machinery or signaling processes (Hanahan and Weinberg 2000; Johnstone et al. 2002). A particularly exciting research area is therefore to try to target these cell death pathways with new drugs. This has been a spectacular, if still underappreciated, success story. Thus small molecules that mimic 
protein-protein interaction surfaces are able to activate apoptosis selectively in cancer cells and are now performing well in clinical trials (Mason et al. 2007; Varfolomeev et al. 2007; Vince et al. 2007; Souers et al. 2013; Condon et al. 2014). These specific small molecule inhibitors have also had an important knock-on effect in that they allow researchers to investigate the function of their targets in acute situations rather than with still comparatively cumbersome genetic techniques (Condon et al. 2014; Wong et al. 2014).

However the converse situation of morbidities where there is too much cell death, such as stroke and ischemia-reperfusion injuries has proven less easy to inhibit. The recent advances in robotic screening of well curated chemical libraries does provide an opportunity to develop such inhibitors and these are increasingly within reach of smaller academic institutions and not just major pharmaceutical companies. With this in mind, Kaylene Simpson and colleagues have outlined how to set up such high-throughput death assays (see Introduction: High-Throughput Approaches to Measuring Cell Death [Saunders et al. 2014]).

Go Forth

In conclusion, there is still much to discover in how, when, and where cell death occurs and what the consequences of deregulated cell death may be for human development and health. There have been incredible advances in our ability to recognize and accurately measure the molecular, biological, and biochemical hallmarks of different forms of cell death and we hope that the protocols described in this collection help you make new discoveries and advance our knowledge of this fascinating field of research.

The authors declare no conflicts of interest.

\section{ACKNOWLEDGMENTS}

Our work is made possible through Victorian State Government Operational Infrastructure Support and Australian Government National Health and Medical Research Council, Independent Research Institutes Infrastructure Support Scheme, and National Health and Medical Research Council research Fellowships to J.S. and R.W.J.

\section{REFERENCES}

Aachoui Y, Sagulenko V, Miao EA, Stacey KJ. 2013. Inflammasome-mediated pyroptotic and apoptotic cell death, and defense against infection. Curr Opin Microbiol 16: 319-326.

Bacon F. 1620. "Novum organum" London.

Begley CG, Ellis LM. 2012. Drug development: Raise standards for preclinical cancer research. Nature 483: 531-533.

Begley CG, Ioannidis JP. 2015. Reproducibility in science: Improving the standard for basic and preclinical research. Circ Res 116: 116-126.

Boatright KM, Renatus M, Scott FL, Sperandio S, Shin H, Pedersen IM, Ricci JE, Edris WA, Sutherlin DP, Green DR, et al. 2003. A unified model for apical caspase activation. Mol Cell 11: 529-541.

Condon SM, Mitsuuchi Y, Deng Y, Laporte MG, Rippin SR, Haimowitz T, Alexander MD, Kumar PT, Hendi MS, Lee YH, et al. 2014. Birinapant -A Smac-mimetic with improved tolerability for the treatment of solid tumors and hematological malignancies. J Med Chem 57: 3666-3677.

Crowley LC, Waterhouse NJ. 2015. Measuring survival of hematopoietic cancer cells with the colony-forming assay in soft agar. Cold Spring Harb Protoc doi: 10.1101/pdb.prot087189.
Crowley LC, Marfell BJ, Scott AP, Boughaba JA, Chojnowski G, Christensen ME, Waterhouse NJ. 2015a. Dead cert: Measuring cell death. Cold Spring Harb Protoc doi: 10.1101/pdb.top070318.

Crowley LC, Christensen ME, Waterhouse NJ. 2015b. Measuring survival of adherent cells with the colony-forming assay. Cold Spring Harb Protoc doi: 10.1101/pdb.prot087171.

Crawford ED, Seaman JE, Barber AE, David DC, Babbitt PC, Burlingame AL, Wells JA. 2012. Conservation of caspase substrates across metazoans suggests hierarchical importance of signaling pathways over specific targets and cleavage site motifs in apoptosis. Cell Death Differ 19: 2040-2048.

Denton D, Kumar S. 2015. Studying apoptosis in Drosophila. Cold Spring Harb Protoc doi: 10.1101/pdb.top070433.

DeVorkin L, Gorski S. 2015. LysoTracker staining to aid in monitoring autophagy in Drosophila. Cold Spring Harb Protoc doi: 10.1101/pdb .prot080325.

Dewson G. 2015. Investigating Bak/Bax activating conformation change by immunoprecipitation. Cold Spring Harb Protoc doi: 10.1101/pdb .prot086454. 
Errington TM, Iorns E, Gunn W, Tan FE, Lomax J, Nosek BA. 2014. An open investigation of the reproducibility of cancer biology research. Elife 3: e04333. doi: 10.7554/eLife.04333.

Feoktistova M, Geserick P, Kellert B, Dimitrova DP, Langlais C, Hupe M, Cain K, Macfarlane M, Hacker G, Leverkus M. 2011. cIAPs Block ripoptosome formation, a RIP1/Caspase-8 containing intracellular cell death complex differentially regulated by cFLIP isoforms. Mol Cell 43: 449-463.

Feoktistova M, Wallberg F, Tenev T, Geserick P, Leverkus M, Meier P. 2015. Techniques to distinguish apoptosis from necroptosis. Cold Spring Harb Protoc doi: 10.1101/pdb.top070375.

Galluzzi L, Bravo-San Pedro JM, Vitale I, Aaronson SA, Abrams JM, Adam D, Alnemri ES, Altucci L, Andrews D, Annicchiarico-Petruzzelli M, et al. 2015. Essential versus accessory aspects of cell death: recommendations of the NCCD 2015. Cell Death Differ 22: 58-73.

Gross O, Yazdi AS, Thomas CJ, Masin M, Heinz LX, Guarda G, Quadroni M, Drexler SK, Tschopp J. 2012. Inflammasome activators induce interleukin- $1 \alpha$ secretion via distinct pathways with differential requirement for the protease function of caspase-1. Immunity 36: 388-400.

Hanahan D, Weinberg RA. 2000. The hallmarks of cancer. Cell 100: 57-70.

Hanayama R, Miyasaka K, Nakaya M, Nagata S. 2006. MFG-E8-dependent clearance of apoptotic cells, and autoimmunity caused by its failure. Curr Dir Autoimmun 9: 162-172.

Jäättelä M, Nylandsted J. 2015. Methods for probing lysosomal membrane permeabilization. Cold Spring Harb Protoc doi: 10.1101/pdb.top070367.

Johnstone RW, Ruefli AA, Lowe SW. 2002. Apoptosis: A link between cancer genetics and chemotherapy. Cell 108: 153-164.

Kroemer G, Galluzzi L, Vandenabeele P, Abrams J, Alnemri ES, Baehrecke EH, Blagosklonny MV, El-Deiry WS, Golstein P, Green DR, et al. 2009. Classification of cell death: Recommendations of the Nomenclature Committee on Cell Death 2009. Cell Death Differ 16: 3-11.

Langlais C, Hughes MA, Cain K, MacFarlane M. 2015. Biochemical analysis of initiator caspase-activating complexes-The apoptosome and DISC. Cold Spring Harb Protoc doi:10.1101/pdb.top070326.

Lant B, Derry WB. 2014. Visualizing apoptosis in embryos and the germline of C. elegans. Cold Spring Harb Protoc doi: 10.1101/pdb.prot080218.

Lindsten T, Ross AJ, King A, Zong WX, Rathmell JC, Shiels HA, Ulrich E, Waymire KG, Mahar P, Frauwirth K, et al. 2000. The combined functions of proapoptotic $\mathrm{Bcl}-2$ family members bak and bax are essential for normal development of multiple tissues. Mol Cell 6: 1389-1399.

Martin SJ, Henry CM, Cullen SP. 2012. A perspective on mammalian caspases as positive and negative regulators of inflammation. Mol Cell 46: 387-397.

Mason KD, Carpinelli MR, Fletcher JI, Collinge JE, Hilton AA, Ellis S, Kelly PN, Ekert PG, Metcalf D, Roberts AW, et al. 2007. Programmed anuclear cell death delimits platelet life span. Cell 128: 1173-1186.

McStay GP, Green DR. 2014. Measuring apoptosis: Caspase inhibitors and activity assays. Cold Spring Harb Protoc doi: 10.1101/pdb.top070359.

Morrison SJ. 2014. Time to do something about reproducibility. Elife 3 doi: 10.7554/eLife.03981.

Nelson C, Baehrecke EH. 2014. Eaten to death. FEBS J 281: 5411-5417.

Newbold A, Martin B, Cullinane C, Bots M. 2014. Measuring apoptosis in mammals in vivo. Cold Spring Harb Protoc doi: 10.1101/pdb.top070417.

Palmisano NJ, Meléndez A. 2015. Detection of autophagy in C. elegans. Cold Spring Harb Protoc doi: 10.1101/pdb.top070466.

Parsons MJ, Rehm M, Bouchier-Hayes L. 2015. Imaging-based methods for assessing caspase activity in single cells. Cold Spring Harb Protoc doi: 10.1101/pdb.top070342.

Pasparakis M, Vandenabeele P. 2015. Necroptosis and its role in inflammation. Nature 517 311-320.

Puleston D, Phadwal K, Watson AS, Soilleux EJ, Chittaranjan S, Bortnik S, Gorski SM, Ktistakis N, Simon AK. 2015. Techniques for the detection of autophagy in primary mammalian cells. Cold Spring Harb Protoc doi: 10.1101/pdb.top070391.

Repnik U, Česen MH, Turk B. 2015. In the footsteps of lysosomal membrane permeabilization. Cold Spring Harb Protoc doi: 10.1101/pdb. top077479.
Rongvaux A, Jackson R, Harman CC, Li T, West AP, de Zoete MR, Wu Y, Yordy B, Lakhani SA, Kuan CY, et al. 2014. Apoptotic caspases prevent the induction of type I interferons by mitochondrial DNA. Cell 159: $1563-1577$.

Sagulenko V, Thygesen SJ, Sester DP, Idris A, Cridland JA, Vajjhala PR, Roberts TL, Schroder K, Vince JE, Hill JM, et al. 2013. AIM2 and NLRP3 inflammasomes activate both apoptotic and pyroptotic death pathways via ASC. Cell Death Differ 20: 1149-1160.

Saunders DN, Falkenberg KJ, Simpson KJ. 2014. High-throughput approaches to measuring cell death. Cold Spring Harb Protoc doi: 10.1101/pdb.top072561.

Segawa K, Kurata S, Yanagihashi Y, Brummelkamp TR, Matsuda F, Nagata S. 2014. Caspase-mediated cleavage of phospholipid flippase for apoptotic phosphatidylserine exposure. Science 344: 1164-1168.

Shalini S, Dorstyn L, Dawar S, Kumar S. 2015. Old, new and emerging functions of caspases. Cell Death Differ 22: 526-539.

Souers AJ, Leverson JD, Boghaert ER, Ackler SL, Catron ND, Chen J, Dayton BD, Ding H, Enschede SH, Fairbrother WJ, et al. 2013. ABT-199, a potent and selective BCL-2 inhibitor, achieves antitumor activity while sparing platelets. Nat Med 19: 202-208.

Suzuki J, Denning DP, Imanishi E, Horvitz HR, Nagata S. 2013. Xk-related protein 8 and CED- 8 promote phosphatidylserine exposure in apoptotic cells. Science 341: 403-406.

Tenev T, Bianchi K, Darding M, Broemer M, Langlais C, Wallberg F, Zachariou A, Lopez J, MacFarlane M, Cain K, et al. 2011. The Ripoptosome, a signaling platform that assembles in response to genotoxic stress and loss of IAPs. Mol Cell 43: 432-448.

Varfolomeev E, Blankenship JW, Wayson SM, Fedorova AV, Kayagaki N, Garg P, Zobel K, Dynek JN, Elliott LO, Wallweber HJ, et al. 2007. IAP antagonists induce autoubiquitination of c-IAPs, NF- $\mathrm{KB}$ activation, and TNF $\alpha$-dependent apoptosis. Cell 131: 669-681.

Vaux DL. 2015. Presentation and interpretation of figures in cell death research publications. In Cell death techniques: A laboratory manual (ed Johnstone, Silke) Cold Spring Harbor Laboratory Press, Cold Spring Harbor, NY.

Vince JE, Wong WW, Khan N, Feltham R, Chau D, Ahmed AU, Benetatos CA, Chunduru SK, Condon SM, McKinlay M, et al. 2007. IAP antagonists target cIAP1 to induce TNFo-dependent apoptosis. Cell 131: 682-693.

Wang H, Yang H, Shivalila CS, Dawlaty MM, Cheng AW, Zhang F, Jaenisch R. 2013. One-step generation of mice carrying mutations in multiple genes by CRISPR/Cas-mediated genome engineering. Cell 153: 910-918.

Wang H, Sun L, Su L, Rizo J, Liu L, Wang LF, Wang FS, Wang X. 2014. Mixed lineage kinase domain-like protein MLKL causes necrotic membrane disruption upon phosphorylation by RIP3. Mol Cell 54: 133-146.

Waterhouse NJ, Trapani JA. 2002. CTL: Caspases terminate life, but that's not the whole story. Tissue Antigens 59: 175-183.

White MJ, McArthur K, Metcalf D, Lane RM, Cambier JC, Herold MJ, van Delft MF, Bedoui S, Lessene G, Ritchie ME, et al. 2014. Apoptotic caspases suppress mtDNA-induced STING-mediated type I IFN production. Cell 159: 1549-1562.

Wong WW, Vince JE, Lalaoui N, Lawlor KE, Chau D, Bankovacki A, Anderton H, Metcalf D, O'Reilly L, Jost PJ, et al. 2014. cIAPs and XIAP regulate myelopoiesis through cytokine production in an RIPK1- and RIPK3-dependent manner. Blood 123: 2562-2572.

Yang H, Wang H, Shivalila CS, Cheng AW, Shi L, Jaenisch R. 2013. One-step generation of mice carrying reporter and conditional alleles by CRISPR/ Cas-mediated genome engineering. Cell 154: 1370-1379.

Yipp BG, Kubes P. 2013. NETosis: How vital is it? Blood 122: 2784-2794.

Yoshida H, Okabe Y, Kawane K, Fukuyama H, Nagata S. 2005. Lethal anemia caused by interferon- $\beta$ produced in mouse embryos carrying undigested DNA. Nat Immunol 6: 49-56.

Zheng TS. Learning from deficiency: Gene targeting of caspases. In: Madame Curie Bioscience Database [Internet]. Austin (TX): Landes Bioscience; 2000. Available from http://www.ncbi.nlm.nih.gov/books/ NBK6153/. 


\section{In the Midst of Life-Cell Death: What Is It, What Is It Good for, and How to Study It}

John Silke and Ricky W. Johnstone

Cold Spring Harb Protoc; doi: 10.1101/pdb.top070508

\begin{tabular}{rc}
$\begin{array}{r}\text { Email Alerting } \\
\text { Service }\end{array}$ & Receive free email alerts when new articles cite this article - click here. \\
\hline $\begin{array}{c}\text { Subject } \\
\text { Categories }\end{array}$ & $\begin{array}{c}\text { Browse articles on similar topics from Cold Spring Harbor Protocols. } \\
\text { Apoptosis Assays (73 articles) } \\
\text { Cell Biology, general (1382 articles) }\end{array}$ \\
\hline
\end{tabular}

